\title{
Endoscopic Submucosal Dissection for Early Gastric Cancer using the Clutch Cutter: a large single-center experience
}

Authors

Institutions
Kazuya Akahoshi', Yasuaki Motomura', Masaru Kubokawa', Junya Gibo', Nobukatsu Kinoshita', Shigeki Osada', Kayo Tokumaru', Taizou Hosokawa', Naru Tomoeda ${ }^{1}$, Yoshihiro Otsuka', Mie Matsuo', Masafumi Oya ${ }^{2}$, Hidenobu Koga ${ }^{3}$, Kazuhiko Nakamura ${ }^{4}$

Institutions are listed at the end of article.
Bibliography

DOI http://dx.doi.org/

10.1055/s-0034-1392509

Published online: 19.8 .2015

Endoscopy International Open

2015; 03: E432-E438

(c) Georg Thieme Verlag KG

Stuttgart · New York

E-ISSN 2196-9736

\section{Corresponding author}

\section{Kazuya Akahoshi, MD, PhD}

Department of

Gastroenterology

Aso lizuka Hospital

3-83 Yoshio

lizuka 820-8505

Japan

Fax: +81-948-29-8747

kakahoshi2@aol.com
Background and study aims: The Clutch Cutter (CC) was developed to reduce the risk of complications related to endoscopic submucosal dissection (ESD) using knives. The CC is able to grasp and coagulate and/or incise the targeted tissue using electrosurgical current, like a biopsy technique. The aim of this study was to evaluate the efficacy and safety of ESD using the CC (ESD-CC) for early gastric cancer (EGC).

Patients and methods: From June 2007 to March 2014, 325 consecutive patients with a diagnosis of EGC were enrolled in this prospective study. They had all satisfied the Japanese gastric cancer treatment guidelines for ESD indication, namely confirmation by preliminary endoscopy, endoscopic ultrasound, and endoscopic biopsies. The CC was used for all steps of ESD (marking, circumferential marginal incision, submucosal dissection, and hemostatic treatment). The therapeutic efficacy and safety were assessed.

\section{Introduction}

$\nabla$

Compared with endoscopic mucosal resection (EMR) for early gastric cancer (EGC), endoscopic submucosal dissection (ESD) has considerable advantages regarding rates of en-bloc resection, curative resection, and local recurrence [1-5]. EMR has subsequently been replaced by ESD. The main problem with ESD using conventional knives is its technical difficulty. Consequently, it is associated with a high rate of complications, foremost of which are a long procedure time and the need for advanced endoscopic techniques $[6,7]$. Conventional devices such as the insulation-tipped electrosurgical knife and needle knife gently push the knife to the tissue and cut using electrosurgical current. Because these tools lack the ability to grasp (accurate targeting and hemostatic effect) and to pull the target tissue (away from the proper muscle layer), they are associated with the potential for major complications such as per-
Results: The en-bloc resection rate was $99.7 \%$ (324/325) and the R0 resection rate was 95.3\% (310/325). The mean operating time was 97.2 minutes. Perforation during ESD-CC occurred in one case $(0.3 \%)$, which was managed with conservative medical treatment after endoscopic closure of the perforation. Post-ESD-CC bleeding occurred in 11 cases (3.4\%), which were successfully treated by endoscopic hemostatic treatment. The R0 resection rate was significantly low in tumors $>20 \mathrm{~mm}(88.9 \%)$, and in the exclusion indication group (73.7\%). Significant differences were seen in the mean operating time, depending upon tumor size, histologic type, location, and indication criteria.

Conclusions: ESD-CC is a technically efficient, safe, and easy method for resecting EGC.

foration and bleeding $[8,9]$. To reduce the risk of complications related to ESD using a conventional knife, Akahoshi and FUJIFILM developed the Clutch Cutter (CC), which can accurately grasp, pull, coagulate, and/or incise the targeted tissue using electrosurgical current $[10,11]$. In our previous pilot study for early gastric neoplasms, we resected tumors safely and easily without unintentional incision by ESD using the CC (ESD-CC) [12]. However, outcomes in a large number of patients with EGC treated by this new method of ESD-CC have not been previously reported. In this study, we assessed the clinical outcomes of ESD-CC for EGC in a large population. 


\section{Patients and methods}

\section{$\nabla$}

\section{Inclusion criteria/curability criteria and ethical considerations}

A total of 325 consecutive patients (228 men, 97 women; mean age 73.7 years, range 35 -95) with EGCs were treated by ESD-CC at Aso Iizuka Hospital from June 2007 to March 2014. They were enrolled based on the clinical indication criteria for ESD proposed by Gotoda et al. [13] and the Japanese Gastric Cancer Association (JGCA) [14] ( Table 1). Resection is considered as curative when all of the following post-ESD histopathological conditions are fulfilled: En-bloc resection, negative horizontal margin, negative vertical margin, no lymphovascular infiltration, and: A) "absolute indication group"-differentiated-type adenocarcinoma without ulcerative findings, of which the depth of invasion is diagnosed as mucosa (pT1a) and the diameter is $\leq 2 \mathrm{~cm}$; B) "Expanded indication group"-B1) differentiated type mucosal cancer (pT1a) without ulcer findings irrespective of tumor size, B2) differentiated type mucosal cancer (pT1a) with ulcer findings $\leq 3 \mathrm{~cm}$ in diameter, B3) differentiated type minute ( $<500$ micron from the muscularis mucosae) submucosal invasive cancer (pT1b) $\leq 3 \mathrm{~cm}$ in size without ulceration, B4) undifferentiated type mucosal cancer (pT1a) $\leq 2 \mathrm{~cm}$ in size without ulceration. Gastrectomy with removal of lymph nodes was recommended for patients with EGCs that did not meet these criteria by post ESD-histological analysis (exclusion criteria group). To evaluate the learning curve of ESD-CC, 325 cases were grouped chronologically into five periods: $\left(1^{\text {st }}\right)$ : cases $1-50 ;\left(2^{\text {nd }}\right)$ : cases $51-100 ;\left(3^{\text {rd }}\right)$ : cases $101-150 ;\left(4^{\text {th }}\right)$ : cases $151-200 ;\left(5^{\text {th }}\right)$ : cases $201-325$. This study was carried out at Aso lizuka Hospital and was approved by its ethics committee. Written informed consent was obtained from all the patients in accordance with the Declaration of Helsinki.

\section{Clutch Cutter (CC)}

The CC (DP2618DT, FUJIFILM Corporation, Tokyo, Japan) ( $\bullet$ Fig. 1) can grasp and cut or coagulate a piece of tissue with electrosurgical current. It has a $0.4 \mathrm{~mm}$-wide and $3.5-\mathrm{mm}$ or 5 -mm long serrated cutting edge to facilitate grasping the tissue. The outer side of the forceps is insulated so that electrosurgical current energy is concentrated at the closed blade to avoid unintentional incision. Furthermore, the forceps is rotatable to the desired orientation. The diameter of this forceps is $2.7 \mathrm{~mm}$. This device is available for all steps of ESD. The forced coagulation mode (VIO 300D; Erbe, Tübingen, Germany) 30W (effect 3) was used for marking, endo cut Q mode (effect 2, duration 3, interval 1) was used for cutting (mucosal incision and submucosal dissection), and the soft coagulation mode $100 \mathrm{~W}$ (effect 5) was used for pre-cut coagulation and hemostatic treatment.

\section{ESD}

ESD was performed by two endoscopists (one endoscopist maneuvered the scope and the other endoscopist maneuvered the CC.). ESD-CC was carried out using a single-channel therapeutic endoscope (EG-450RD5, Fujifilm) or a two-channel multi-bending endoscope (GIF-2T240M; Olympus, Tokyo, Japan). A long transparent hood (F-01, Top Co. Ltd., Tokyo, Japan) was attached to the endoscopic tip to facilitate submucosal dissection by elevating the lesion. The ESD-CC technique was as follows ( $\bullet$ Fig. 2) (VTR. 1). Marking dots were placed a few millimeters outside the margin of the lesion by CC in closed mode. Next, hyaluronic acid solution (MucoUp: Johnson and Johnson Co., Tokyo, Japan) mixed with a small volume of epinephrine and indigo carmine dye was
Table 1 JGCA indication criteria for ESD for early gastric cancer.

\begin{tabular}{|l}
\hline Absolute indication \\
Tumor size $<2 \mathrm{~cm}$, histologically of differentiated type, \\
T1a, ulcer (-) \\
Expanded indication \\
(a) Tumor size $>2 \mathrm{~cm}$, histologically of differentiated type, \\
\hline T1a, ulcer (-) \\
\hline (b) Tumor size $<3 \mathrm{~cm}$, histologically of differentiated type, \\
\hline T1a, ulcer (+) \\
(c) Tumor size $<2 \mathrm{~cm}$, histologically of undifferentiated type, \\
T1a, ulcer (-) \\
Exclusion indication \\
Not satisfying any of the above criteria
\end{tabular}

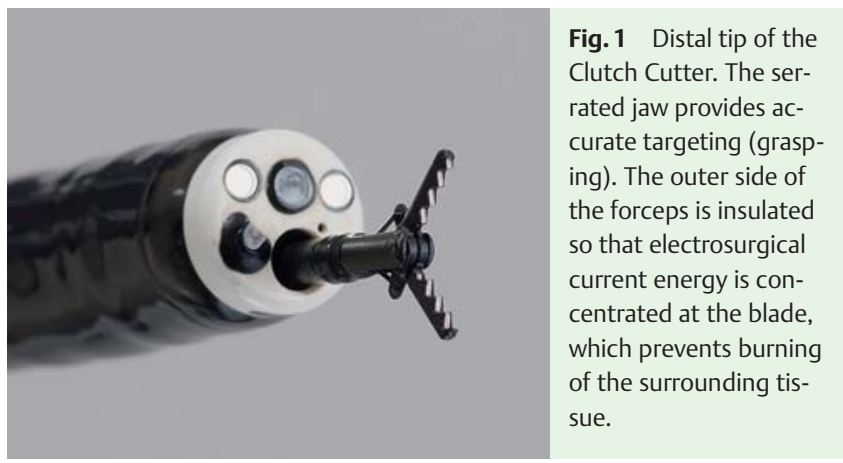

injected into the submucosal layer. A mucosal incision and submucosal dissection were performed to completely remove the lesion using the CC. The bleeding vessel (artery or vein) was grasped, pulled/lifted and coagulated with the CC using electrosurgical current to stop the bleeding. Finally, the lesion was completely resected. All cutting steps consisted of 1) grasping step; 2) pull or lift up step; 3 ) pre-cut coagulation step with soft coagulation (if existence of blood vessel was suspected); and 4) cutting step with endo cut Q $(\bullet$ Fig.3).

\section{Histopathological evaluation}

The excised specimens were sectioned perpendicularly at 2-mm intervals. According to the Japanese classification for Gastric Cancer, the histology was divided into differentiated adenocarcinoma (well or moderately differentiated adenocarcinoma or papillary adenocarcinoma) or undifferentiated adenocarcinoma (poorly differentiated adenocarcinoma or signet-ring-cell carcinoma). Tumor size, depth of invasion, presence of ulcerative changes, lymphatic and vascular involvement, and tumor involvement to the horizontal and vertical margins were assessed.

\section{Assessment of therapeutic efficacy and complications}

The operating time was calculated as the time from the beginning of submucosal injection to the end of submucosal dissection. Resections were defined as "en bloc" when a lesion was resected in one piece and the resection margins were macroscopically tumor-free. Extension of cancer cells to the resected margin was evaluated as R0 (en-bloc resection with the lateral and basal resection margins free of cancer), R1 (incomplete resection when the cancer extended into the lateral or basal margins), or Rx (not evaluable when the margins were not evaluable as a result of the artificial effects of coagulation necrosis or multi-piece resection). All patients stayed in the hospital for 7 days following the procedure, after which follow-up endoscopic examinations were conducted at 2 days, and 2 (or 3), 9, and 15 months, and annually 

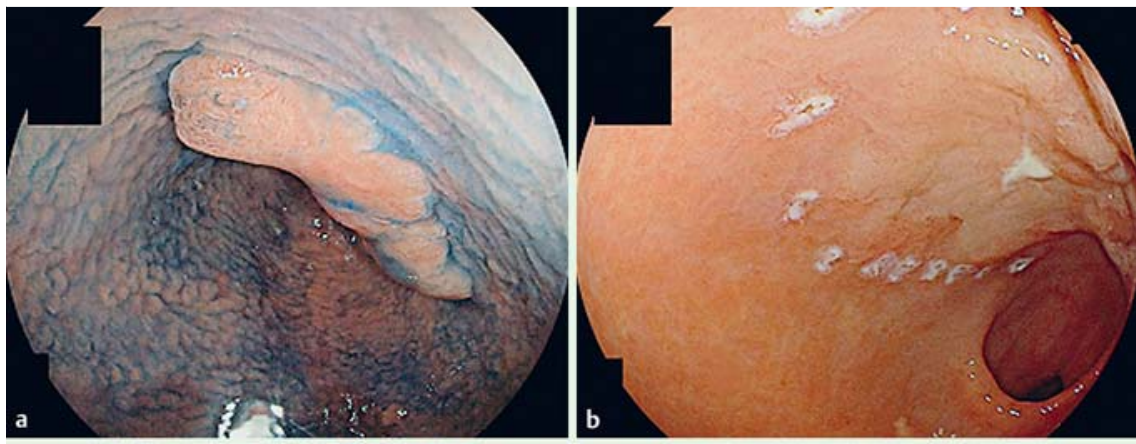

Fig. 2 Endoscopic view of the ESD procedure using the CC. a Chromoendoscopy with indigo carmine to demarcate the lesion. $\mathbf{b}$ Marks are made at several points along the outline of the lesion with a coagulation current. c The mucosa is incised outside the marker dots to separate the lesion from the surrounding non-neoplastic mucosa using the CC. d The submucosal connective tissue immediately beneath the lesion is gradually dissected from the muscle layer using the CC. e The lesion is cut completely from the muscle layer. $\mathbf{f}$ The resected specimen shows en-bloc resection of the lesion.
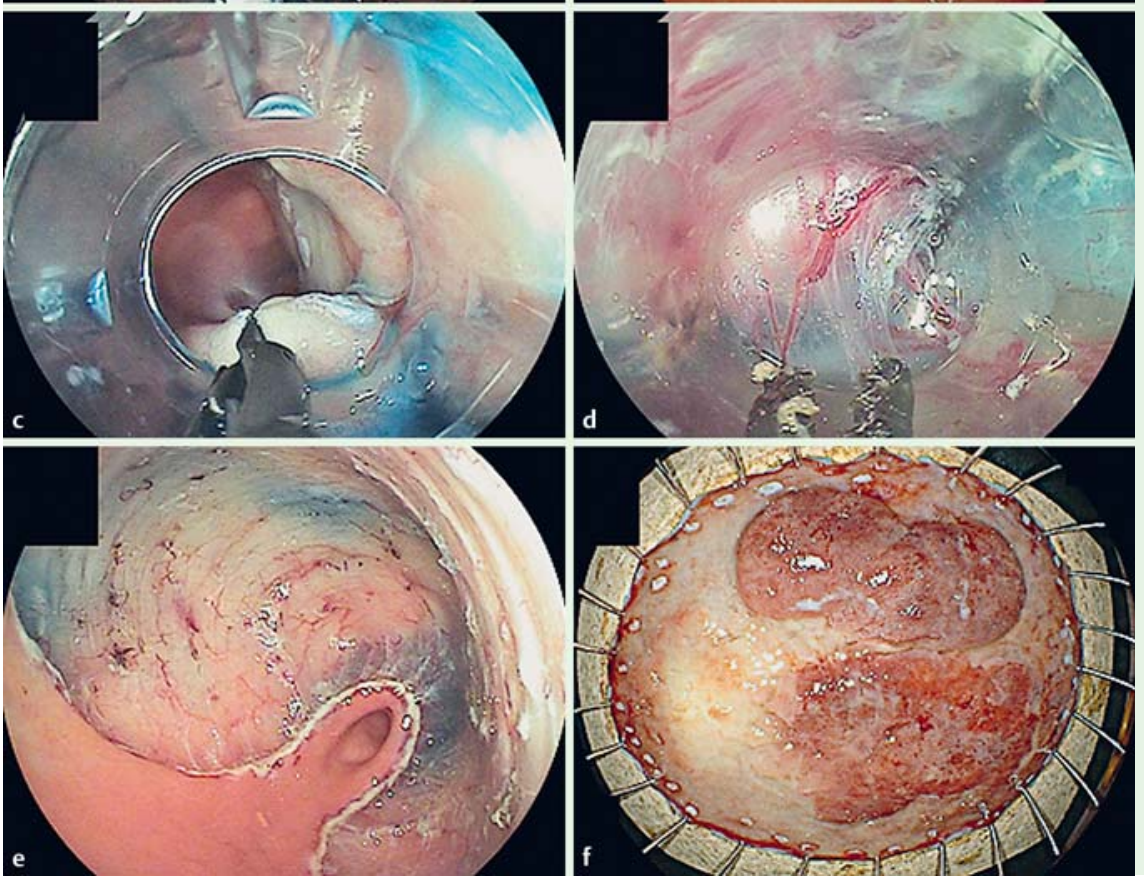

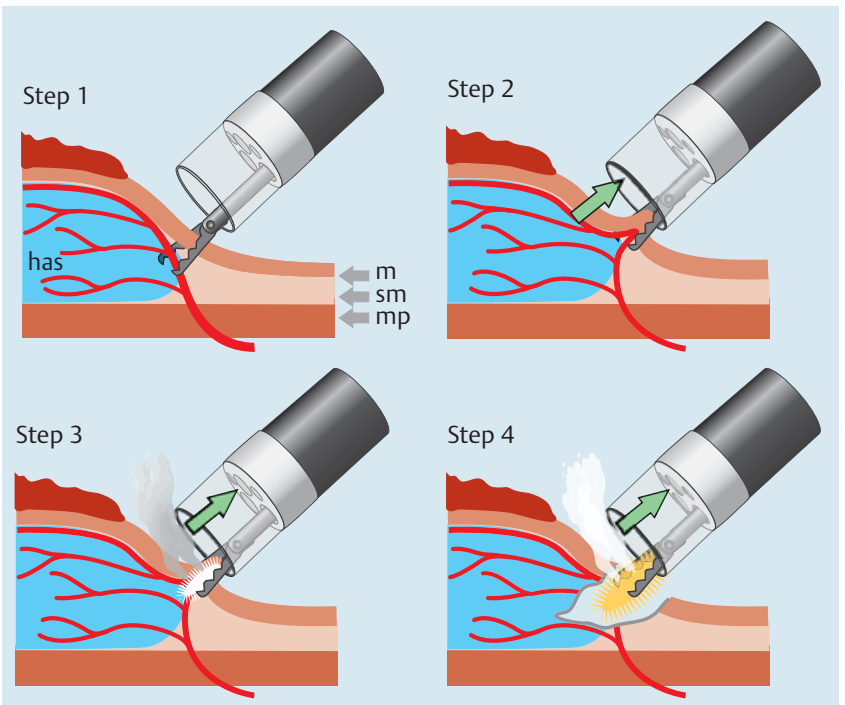

Fig. 3 Basic technique of the Clutch Cutter ESD. Step 1 (Accurate targetting): The target tissue is accurately grasped by the CC. Step 2 (Leaving from the proper muscle layer): The grasped tissue is pulled (or lifted up) to avoid electrical damage to the proper muscle layer. Step 3 (Pre-cut coagulation): The grasped tissue including the blood vessel is coagulated for prevention of intraoperative bleeding. Step 4 (Cut): The grasped tissue is cut using electrosurgical current for the incision. Arrow: Direction of pull, m: mucosa, sm: submucosa, mp: muscularis propria, has: hyaluronic acid solution, bv: blood vessel. thereafter. All patients were given a proton pump inhibitor for a minimum of 8 weeks.

\section{Statistical analysis}

All data analysis was conducted with a statistical software package (SAS version 9.2 and JMP version 8.0.1, SAS Institute Inc, NC, USA) The significance of differences in the lesion's features and the $\mathrm{R} 0$ resection rate of ESD-CC was determined using the $\mathrm{X}^{2}$ test. The significance of any differences in the lesion's features and the mean operating time of ESD-CC were determined using the Kruskal-Wallis test. A P value of less than 0.05 was considered to be significant.

\section{Results \\ $\nabla$}

Clinicopathological characteristics are shown in Table 2. The male: female ratio was 2.4:1 (228/97) and the patients' mean age was 73.7 years (range 35 - 95 years). After histological analysis of the resected specimens obtained by this procedure, the 325 patients were divided into three groups ( $\bullet$ Table 1 ): Group 1 fulfilled the traditionally accepted indications (absolute indication group); Group 2 did not meet the absolute indication criteria but did meet the expanded indication criteria (the expanded indication group), and Group 3 did not meet the proposed criteria (exclusion indication group). The 38 patients in the exclusion-indication group were urged to undergo surgery. Nineteen patients 
Table 2 Clinicopathological characteristics $(\mathrm{N}=325)$.

\begin{tabular}{|c|c|}
\hline Sex, male/female & 228/97 \\
\hline Mean \pm SD (range) age (years) & $73.7 \pm 9.0(35-95)$ \\
\hline \multicolumn{2}{|l|}{ Histologic type (\%) } \\
\hline Differentiated type adenocarcinoma & $315(97 \%)$ \\
\hline Undifferentiated type adenocarcinoma & $10(3 \%)$ \\
\hline \multicolumn{2}{|l|}{ Location (\%) } \\
\hline Lower & $131(40 \%)$ \\
\hline Middle & $99(31 \%)$ \\
\hline Upper & $95(29 \%)$ \\
\hline \multicolumn{2}{|l|}{ Indication criteria for ESD } \\
\hline Absolute indication group & $204(63 \%)$ \\
\hline Expanded indication group & $83(25 \%)$ \\
\hline Exclusion indication group & $38(12 \%)$ \\
\hline
\end{tabular}

Table 3 Technical results of ESD with the Clutch Cutter $(\mathrm{N}=325)$.

\begin{tabular}{|lc|}
\hline Mean \pm SD size of lesion, $\mathrm{mm}$ (range) & $17.3 \pm 12.1(2-74)$ \\
\hline Mean \pm SD size of resected specimen, $\mathrm{mm}$ (Range) & $46.7 \pm 15.5(18-95)$ \\
\hline En-bloc resection rate (\%) & $324 / 325(99.7 \%)$ \\
\hline R0 resection rate (\%) & $310 / 325(95.3 \%)$ \\
\hline Complication rate & $12 / 325(3.6 \%)$ \\
\hline Intraoperative perforation rate & $1 / 325(0.3 \%)$ \\
\hline Intraoperative uncontrollable bleeding rate & $0 / 325(0 \%)$ \\
\hline Postoperative perforation rate & $0 / 325(0 \%)$ \\
\hline Postoperative bleeding rate & $11 / 325(3.4 \%)$ \\
\hline
\end{tabular}

have been referred for gastrectomy with lymph node dissection. Postoperative histological findings were no gastric residual cancer without lymph node metastasis in 17 patients, no gastric residual cancer with lymph node metastasis in one patient, and residual cancer (subserosal cancer) without lymph node metastasis in the other patient. The remaining 19 patients refused surgery and were followed up.

The technical outcome is summarized in Table 3. The grasping and pull or lift-up steps before cutting the targeted tissue provided good visualization of the target area and allowed the use of sufficient pre-cut coagulation. In three patients $(0.9 \%)$, difficulties were encountered with the endoscopic approach to the target tissue during submucosal dissection. These lesions were successfully resected (en-bloc resection) using a polypectomy snare. The mean size of the EGCs and resected specimens was $17.3 \pm$ $12.1 \mathrm{~mm}$ and $46.7 \pm 15.5 \mathrm{~mm}$, respectively. The en-bloc resection rate and R0 resection rate were $99.7 \%$ and $95.3 \%$ respectively. The mean operating time was 97.2 minutes.

- Table 4 lists the R0 resection rate and operating time according to clinicopathological factors. R0 resection rates differed significantly according to tumor size and indication criteria. Mean operating time also differed significantly according to tumor size, histologic type, location, and indication criteria.

During ESD-CC, minor bleeding occurred in most cases, but prompt hemostasis was achieved with the CC (VTR. 2). Unsuccessful hemostasis using the CC for intraoperative bleeding occurred in eight cases (2.4\%), but hemostasis was obtained with the injection of hypertonic saline epinephrine solution and/or coagulation with a Coagrasper (FD-410LR; Olympus). No uncontrollable bleeding was encountered. Postoperative bleeding was seen in $3.4 \%$ (11 of 325 ). However, all of the hemorrhagic episodes were successfully managed with endoscopic clipping or coagulation. In one case $(0.3 \%)$, endoscopic perforation occurred during cutting when proper muscle was wrongly identified as fibrotic submucosal tissue. That patient was successfully treated
Table 4 R0 resection rate and operating time for ESD using the Clutch Cutter according to clinicopathological factors $(\mathrm{N}=325)$.

\begin{tabular}{|c|c|}
\hline \multicolumn{2}{|c|}{ R0 resection rate according to clinicopathological factors (\%) } \\
\hline \multicolumn{2}{|l|}{ Tumor size } \\
\hline $0-20 \mathrm{~mm}$ & $230 / 235(97.9 \%)$ \\
\hline $21-\mathrm{mm}$ & $80 / 90(88.9 \%)$ \\
\hline$P$ value & $P<0.0001$ \\
\hline \multicolumn{2}{|l|}{ Histologic type } \\
\hline Differentiated type adenocarcinoma & $301 / 315(95.6 \%)$ \\
\hline Undifferentiated type adenocarcinoma & $9 / 10(90 \%)$ \\
\hline$P$ value & NS \\
\hline \multicolumn{2}{|l|}{ Location } \\
\hline Lower & $127 / 131(96.9 \%)$ \\
\hline Middle & $91 / 99(91.9 \%)$ \\
\hline Upper & $92 / 95(96.8 \%)$ \\
\hline$P$ value & NS \\
\hline \multicolumn{2}{|l|}{ Indication criteria } \\
\hline Absolute indication group & $201 / 204(98.5 \%)$ \\
\hline Expanded indication group & $81 / 83(97.6 \%)$ \\
\hline Exclusion indication group & $28 / 38(73.7 \%)$ \\
\hline$P$ value & $P<0.0001$ \\
\hline \multicolumn{2}{|c|}{$\begin{array}{l}\text { Operating time (minutes) according to clinicopathological factors } \\
\text { (Range) }\end{array}$} \\
\hline \multicolumn{2}{|l|}{ Tumor size } \\
\hline $0-20 \mathrm{~mm}$ & $82.4 \pm 58.8(14-423)$ \\
\hline $21-\mathrm{mm}$ & $135.4 \pm 63.2(20-340)$ \\
\hline$P$ value & $P<0.0001$ \\
\hline \multicolumn{2}{|l|}{ Histologic type } \\
\hline Differentiated type adenocarcinoma & $95.5 \pm 62.3(14-379)$ \\
\hline Undifferentiated type adenocarcinoma & $149 \pm 106.4(51-423)$ \\
\hline$P$ value & $P<0.05$ \\
\hline \multicolumn{2}{|l|}{ Location } \\
\hline Lower & $73.9 \pm 44.9(15-230)$ \\
\hline Middle & $108.8 \pm 58.8(19-300)$ \\
\hline Upper & $117.2 \pm 81.6(14-423)$ \\
\hline$P$ value & $P<0.0001$ \\
\hline \multicolumn{2}{|l|}{ Indication criteria } \\
\hline Absolute indication group & $78.8 \pm 54.7(14-379)$ \\
\hline Expanded indication group & $128.7 \pm 68.0(33-423)$ \\
\hline Exclusion indication group & $126.3 \pm 68.9(20-340)$ \\
\hline$P$ value & $P<0.0001$ \\
\hline
\end{tabular}

with endoscopic clipping. There was no delayed perforation after ESD-CC.

The learning curve demonstrated changes in operator proficiency over time ( $\bullet$ Fig.4). Proficiency was expressed as operating time only and did not reflect the rates of R0 resection or perforation. The operating time in the first period was significantly longer than in the remaining periods $(P<0.01)$.

\section{Discussion}

\section{$\nabla$}

ESD for EGC is a widely accepted and well-established procedure because of it has a high tumor eradication rate and is less invasive than surgery. The major advantage of ESD over EMR is the high rate of en-bloc resection, regardless of the size, shape, coexisting ulcer, or location of the lesion [1-5]. However, ESD is a more difficult and meticulous technique than EMR, and sometimes is associated with serious adverse events. Despite its technical difficulties, ESD using various knife devices has been shown by experts in limited high-volume centers to be effective and relatively safe for treatment of EGC [1 -7]. ESD using knife devices is tech- 


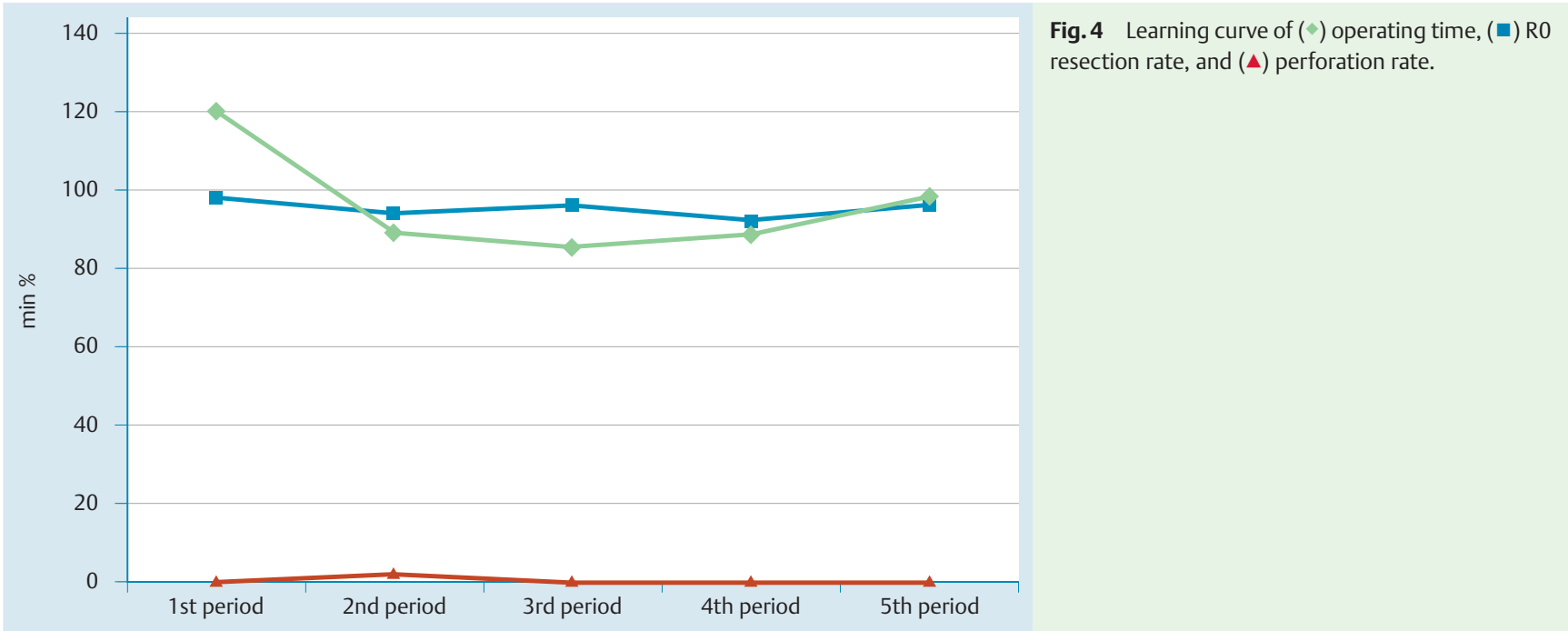

nically difficult and carries a substantial risk of perforation and bleeding $[2,4,6]$. The basic counter-measure for such complications is sufficient submucosal lifting by injected solution, which is very effective for all ESD methods including ESD-CC. When circumferential incision is completed prior to submucosal dissection, submucosal lifting often is difficult because of escape of the injected solution. We usually perform partial mucosal incision followed by partial submucosal dissection and repeat it up to completion of the en-bloc resection to prevent insufficient submucosal lifting, especially for broad lesions. The inevitable risk factors for ESD-related complications that are associated with knife devices are defects of fixation (inaccurate targeting) and compression (hemostatic effect) and pushing the knife to the target tissue (push force basically in the direction of the proper muscle) with electric discharge [8]. Our new device, CC, can be used to grasp, pull (or lift up), and incise or coagulate the targeted tissue with electrosurgical current.

The CC has four characteristic safe mechanical procedures: 1) fixation (accurate targeting); 2) pull or lift up (away from the proper muscle layer); 3) compression (high hemostatic capability); and 4) outside insulation (minimization of outside electric damage) [8-12]. In this study, there was a $0.3 \%$ perforation rate (only one case), no unintentional incision, and we were able to stop the intraoperative bleeding quickly and easily by CC without changing the device (VTR. 2). ESD-CC is accomplished merely with grasp, pull (or lift up), and cut or coagulate steps, and it is as easy and simple as a standard-bite biopsy technique ( $\bullet$ Fig. 3 ). Furthermore, it was possible to perform all steps of ESD with only one instrument: the $\mathrm{CC}$. We hypothesize that the advantages of ESD-CC will reduce the difficulty, risk of complication, and costs involved in performing ESD $[8,9]$.

The ESD-CC is available for different organs. As of February 2015 (including our previously reported studies[9]), in our institute, we had performed ESD-CC (long-type for the stomach, shorttype for the remaining organs) on 852 consecutive patients with a diagnosis of early-stage digestive tract tumor including adenoma (organ, number of patients, en-bloc resection rate, perforation rate, bleeding rate; lower pharynx, five patients, $80 \%, 0 \%$, $0 \%$; esophagus, 66 patients, $100 \%, 1.5 \%, 1.5 \%$; stomach, 524 patients, 99\%, 0.2\%, 3\%; duodenum, eight patients, $100 \%, 0 \%, 0 \%$; ileum, one patient, $100 \%, 0 \%, 0 \%$; colon and rectum, 248 patients, $95 \%, 1.6 \%, 1.6 \%$ ) using the same method (unpublished data).
In this ESD-CC study, en-bloc resection was achieved in $99.7 \%$ of the patients. That is comparable to results in other studies $(94.9 \%-97.7 \%)[3,5,15-17]$. The rate of R0 resection by ESD-CC was $95.3 \%$. The reported rate of R0 resection using a knife device ranges from $82 \%$ to $95.5 \%[4,7,18]$. The mean operating time for ESD-CC was 97.2 minutes, versus reported mean operating times for ESD using knife devices ranging from 47.8 to 108.1 minutes $[5,7,19]$. The R0 resection rate and procedure times for ESD-CC appear to be similar to those for conventional knife ESD. Furthermore, the R0 resection rate with ESD-CC was high (over 88\%) irrespective of differences in tumor size, histologic type, location, and indication type (not counting the exclusion indication group).

Neuhaus [20] reported that European results for ESD indicate lower rates of complete resection and higher morbidity compared to most trials from Asia, and they also demonstrate an unfavorable outcome at the beginning of the learning curve even after training in an experimental setting. Probst et al. [21] showed a learning curve for ESD using knife devices resulting in a decreased procedural duration and an increased rate of complete en-bloc resection over time. However, ESD-CC is a simple technique (grasp $>>$ pull $>>$ cut or coagulate) similar to a standard bite biopsy. Because to the ease or learning ESD-CC, we achieved a high complete resection rate and an extremely low rate of morbidity, although we had little experience with conventional knife ESD. Based on our analysis of the learning curve, approximately 50 procedures must be carried out to acquire skill with performing ESD-CC for early gastric cancers.

Risk of perforation associated with the ESD procedure is divided into two groups, depending on the time of onset. Intraoperative perforation is due mainly to penetration of an electrosurgical knife through the proper muscle layer during ESD. The other type of perforation is postoperative, which mainly occurs 1 to 2 days after the ESD procedure. The rate of intraoperative perforation during gastric ESD ranges from $1.2 \%$ to $8.2 \%$ [5,22-24]. To prevent intraoperative perforation, it is necessary to avoid electric sparkling to the proper muscle layer, which occurs mainly because of unintentional incision. The safe mechanism of CC, such as the pull effect and outside insulation, is very effective in preventing intraoperative perforation. In our ESD-CC study, we encountered only one endoscopic perforation ( $0.3 \%)$ due to misidentification of the proper muscle layer as fibrotic tissue, not 
due to unintentional incision. This patient was successfully treated with immediate closure of the perforation by endoscopic clipping.

Postoperative perforation is reported to be a rare complication; however, once it occurs, it can lead to serious conditions that often require emergency surgery $[25,26]$. The frequency is reported to be about $0.45 \%$ [26]. In theory, excessive thermal damage to the muscle layer may be one of the causes of postoperative perforation. Usually, hemostasis using the conventional knife requires a gentle push of the knife to the visible vessel with electrosurgical coagulation. Furthermore, most hemostatic devices have no outside insulation. Such shortcomings of conventional ESD devices may lead to postoperative perforation. The pull effect and outside insulation of the CC is very effective in preventing postoperative perforation. In this ESD-CC study, we encountered no postoperative perforations.

Bleeding is the most common major complication of ESD and is divided into two types, based on time of onset. Intraoperative bleeding is defined as any bleeding occurring during the ESD procedure, whereas postoperative bleeding occurs after the ESD procedure. Although intraoperative bleeding occurs frequently, it is difficult to measure its severity. Oda et al. reported that the rate of significant intraoperative bleeding was 7\% [27]. Prevention and early control of any intraoperative bleeding is vital because bleeding can impair the endoscopic view, resulting in an increase in procedure time and intraoperative perforation. Preventive hemostatic coagulation of visible blood vessels and the quick cessation of unintentional bleeding are very important for obtaining a safe cure. The CC has accurate and sufficient hemostatic effects such as fixation (accurate targeting), pull or lift up (from the proper muscle layer), and compression (high hemostatic capability) $[8,9]$. Therefore, we were able to perform sufficient pre-cut coagulation and stop the unintentional hemorrhage quickly using the CC without changing the device. There was no uncontrollable intraoperative bleeding in our study.

Postoperative bleeding is reported to occur in $5.3 \%$ to $15.6 \%$ of gastric ESD cases [5,22, 27 - 30], usually within a week after ESD. Therefore, in our institution, patients are observed in the hospital for 7 days following the procedure. ESD-CC is available for pre-cut

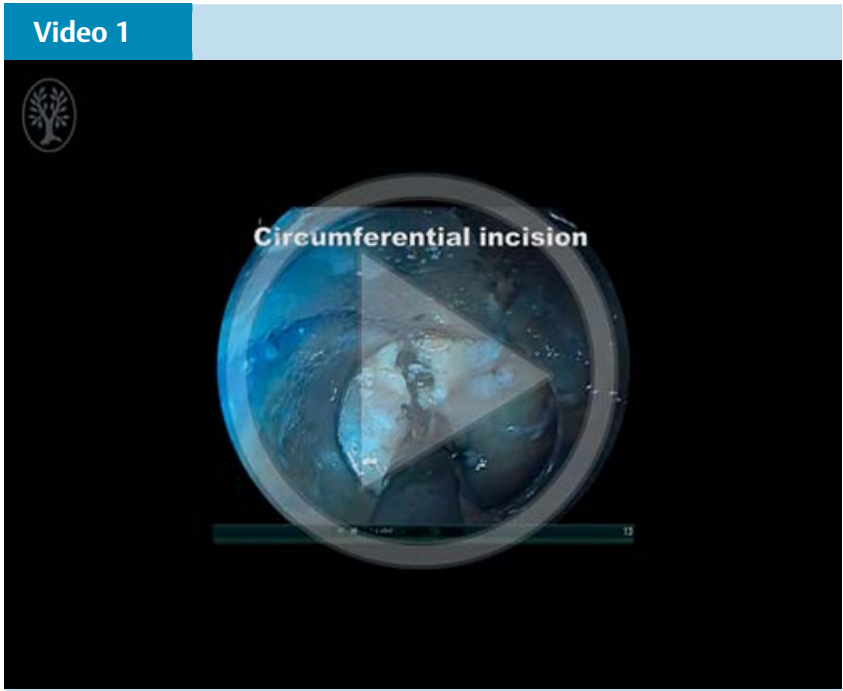

VTR of the procedure of ESD-CC of type $0-I+$ Ila early gastric cancer. Online content including video sequences viewable at: http://dx.doi.org/10.1055/ s-0034-1392509 coagulation and preventive coagulation for visible blood vessels of the ESD ulcer base. In this study, the postoperative bleeding rate was relatively low (3.4\%) as compared with that for conventional knife ESD. In our series, we performed second-look endoscopy in all cases. If a risky exposed vessel with clot or oozing bleeding was found during second-look endoscopy, we performed additional coagulation. The second-look endoscopy may have had a positive effect on our low rate of delayed postoperative hemorrhage.

Several specific knives or devices are required for each step in conventional ESD $[8,9]$. With ESD-CC, on the other hand, a single device is used (CC). Before ESD-CC was introduced in our institute, we used a needle knife for marking and making a starting hole, an insulation - tipped diathermic knife for circumferential incision and submucosal excision steps, and a hemostatic forceps for intraoperative bleeding. At least three devices were required for each session of ESD. In this study, we used only one device (CC) for all ESD steps. The ESD-CC reduces the number of devices and the cost of ESD [9].

In conclusion, the results of our large, single-center series suggest that ESD-CC is an excellent endoscopic treatment for EGC because it is a single-device method, effective, safe, and technically simple to perform. Extensive controlled, randomized studies, e.g., vs. IT knife, vs. needle knife or vs. other devices, are necessary to fully evaluate the usefulness of our method, not only in Japan but also in Western countries, given the significant difference in ESD experience.

Competing Interests: Kazuya Akahoshi and Hidefumi Akahane (FUJIFILM) have applied for a patent in Europe for the Clutch Cutter describes in this article. Japan, China, and the USA have already granted the patent.

\section{Institutions}

Department of Gastroenterology, Aso lizuka Hospital, lizuka, 820-8505 Japan Department of Pathology, Aso lizuka Hospital, lizuka, 820-8505 Japan 3 Clinical Research Support Office, Aso lizuka Hospital, lizuka, 820-8505 Japan ${ }^{4}$ Department of Medicine and Bioregulatory Science, Graduate School of Medical Sciences, Kyushu University, Fukuoka 812-8582, Japan

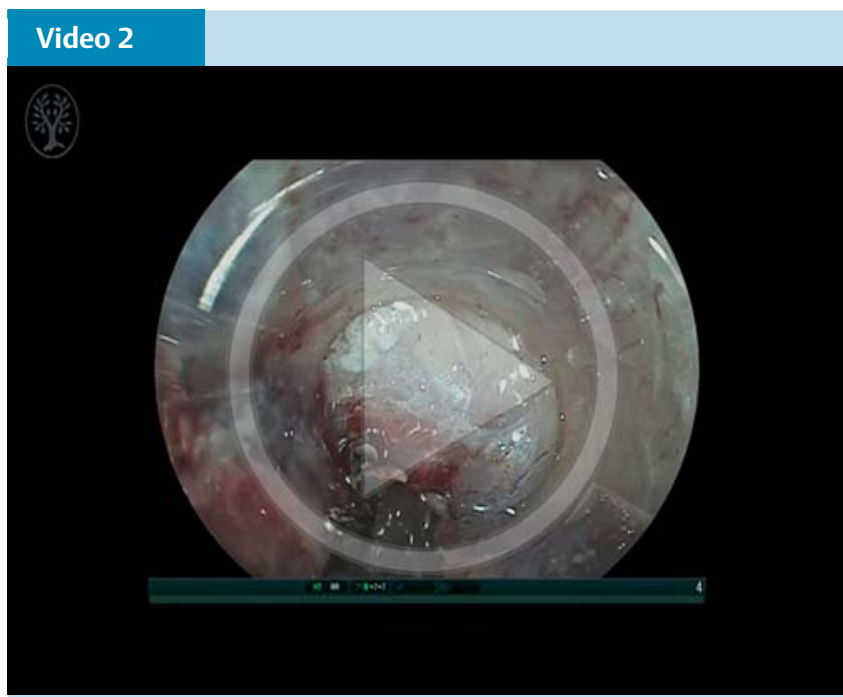

VTR of the hemostasis of intraoperative bleeding by the CC. Online content including video sequences viewable at: http://dx.doi.org/10.1055/s-00341392509 


\section{References}

1 Ono H, Kondo H, Gotoda $T$ et al. Endoscopic mucosal resection for treatment of early gastric cancer. Gut 2001; 48: 225 - 229

2 Kakushima N, Fujishiro M. Endoscopic submucosal dissection for gastrointestinal neoplasms. World. J. Gastroenterol 2008; 14: 2962 - 2967

3 Isomoto H, Shikuwa S, Yamaguchi $N$ et al. Endoscopic submucosal dissection for early gastric cancer: a large-scale feasibility study. Gut 2009; 58: 331 - 336

4 Lian J, Chen S, Zhang Yet al. A meta-analysis of endoscopic submucosal dissection and EMR for early gastric cancer. Gastrointest Endosc 2012; 76: $763-770$

5 Chung II, Lee JH, Lee SH et al. Therapeutic outcomes in 1000 cases of endoscopic submucosal dissection for early gastric neoplasms: Korean ESD Study Group multicenter study. Gastrointest Endosc 2009; 69: $1228-1235$

6 Saito I, Tsuji Y, Niimi Ket al. Complications related to gastric endoscopic submucosal dissection and their managements. Clin Endosc 2014; 47: $398-403$

7 Yamamoto Y, Fujisaki J, Ishiyama A et al. Current status of training for endoscopic submucosal dissection for gastric epithelial neoplasm at Cancer Institute Hospital, Japanese Foundation for Cancer Research, a famous Japanese hospital. Dig Endosc 2012; 24 : 01148 - 153

8 Akahoshi K, Akahane $H$. A new breakthrough: ESD using a newly developed grasping type scissor forceps for early gastrointestinal tract neoplasms. World J Gastrointest Endosc 2010; 2: 90-96

9 Akahoshi K, Akahane H, Motomura Yet al. A new approach: Endoscopic submucosal dissection using the Clutch Cutter for early stage digestive tract tumors. Digestion 2012; 85: $80-84$

10 Akahoshi K, Akahane H, Murata A et al. Endoscopic submucosal dissection using a novel grasping type scissors forceps. Endoscopy 2007; 39: $1103-1105$

11 Akahoshi K, Honda K, Akahane $H$ et al. Endoscopic submucosal dissection using a grasping type scissors forceps: a preliminary clinical study. Gastrointest Endosc 2008; 67: 1128-1133

12 Akahoshi K, Honda K, Motomura Yet al. Endoscopic submucosal dissection using a grasping type scissors forceps for early gastric cancers and adenomas. Dig Endosc 2011; 23: 24-29

13 Gotoda T, Yanagisawa A, Sasako M et al. Incidence of lymph node metastasis from early gastric cancer: estimation with a large number of cases at two large centers. Gastric Cancer 2000; 3: 219-225

14 Japanese Cancer Association. Japanese gastric cancer treatment guidelines 2010 (ver. 3). Gastric Cancer 2011; 14: 113-123

15 Min YW, Min BH, Lee JH et al. Endoscopic treatment for early gastric cancer. World J Gastroenterol 2014; 20: 4566 - 4573
16 Gotoda T. A large endoscopic resection by endoscopic submucosal dissection procedure for early gastric cancer. Clin Gastroenterol Hepatol 2005; 3: 71 -S73

17 Tanaka $M$, Ono $H$, Hasuike $N$ et al. Endoscopic submucosal dissection of early gastric cancer. Digestion 2008; 77: 0123 - 28

18 Nakamoto S, Sakai Y, Kasanuki J et al. Indications for the use of endoscopic mucosal resection for early gastric cancer in Japan: a comparative study with endoscopic submucosal dissection. Endoscopy 2009; 41: $746-750$

19 Białek A, Wiechowska-Kozłowska A, Pertkiewicz J et al. Endoscopic submucosal dissection for the treatment of neoplastic lesions in the gastrointestinal tract. World J Gastroenterol 2013; 19: 1953 -1961

20 Neuhaus $H$. Endoscopic submucosal dissection in the upper gastrointestinal tract: present and future view of Europe. Dig. Endosc 2009; 21: s4-s6

21 Probst A, Golger D, Arnholdt $H$ et al. Endoscopic submucosal dissection of early gastric cancers, flat adenomas, and submucosal tumors in the gastrointestinal tract. Clin Gastroenterol Hepatol 2009; 7: 149-155

22 Mannen K, Tsunada S, Hara $M$ et al. Risk factors for complications of endoscopic submucosal dissection in gastric tumors: analysis of 478 lesions. J Gastroenterol 2010; 45: 30-36

23 Watari J, Tomita T, Toyoshima F et al. Clinical outcomes and risk factors for perforation in gastric endoscopic submucosal dissection: a prospective pilot study. World J Gastrointest Endosc 2013; 5: 281 - 287

24 Nonaka $\mathrm{K}$, Kita $\mathrm{H}$. Endoscopic submucosal dissection for early gastric cancer. J Cancer Ther 2013; 4: 26-32

25 Ikezawa K, Michida T, Iwahashi K et al. Delayed perforation occurring after endoscopic submucosal dissection for early gastric cancer. Gastric Cancer 2012; 15: $111-114$

26 Hanaoka $N$, Uedo $N$, Ishihara $R$ et al. Clinical features and outcomes of delayed perforation after endoscopic submucosal dissection for early gastric cancer. Endoscopy 2010; 42: 1112 - 1115

27 Oda I, Gotoda T, Hamanaka H et al. Endoscopic submucosal dissection for early gastric cancer: technical feasibility, operation time and complications from a large consecutive series. Dig Endosc 2005; 17: 54 - 58

28 Tsuji $Y$, Ohata $K$, Ito $T$ et al. Risk factors for bleeding after endoscopic submucosal dissection for gastric lesions. World J Gastroenterol 2010; 16: $2913-2917$

29 Fujishiro M, Chiu PW, Wang HP. Role of antisecretory agents for gastric endoscopic submucosal dissection. Dig Endosc 2013; 25: 86-93

30 Koh R, Hirasawa K, Yahara $S$ et al. Antithrombotic drugs are risk factors for delayed postoperative bleeding after endoscopic submucosal dissection for gastric neoplasms. Gastrointest Endosc 2013; 78: 476-483 